\title{
Stain Resistance of Maxillofacial Materials
}

\author{
A. KORAN, J. M. POWERS, P. J. LEPEAK, and R. G. CRAIG \\ School of Dentistry, The University of Michigan, Ann Arbor, Michigan 48109
}

The resistance of three silicone and one polyvinyl chloride maxillofacial materials to staining by tea, lipstick, and disclosing solution was measured by reflectance spectrophotometry. Changes in color caused by staining were larger than changes caused by color instability of the base elastomers or pigments under conditions of accelerated aging.

J Dent Res 58(5):1455-1460, May 1979

\section{Introduction.}

Maxillofacial appliances generally have a short life in a service environment. These appliances fail as a result of inherent problems with static and dynamic properties over varying periods of time and by color instability. These appliances are expensive to fabricate, and many patients cannot afford frequent replacement. This also taxes the facilities that are available to help these patients.

In a previous study ${ }^{1}$ the color stability of the base elastomers was evaluated under conditions of accelerated aging. All color changes observed were small considering the problems with maintaining the esthetics of maxillofacial appliances in a service environment.

In a subsequent study ${ }^{2}$ the color stability of maxillofacial pigments was measured under conditions of accelerated aging in order to understand the mechanisms of color degradation observed clinically. Of the 11 pigments studied, seven pigments demonstrated good to excellent color stability, while four of the pigments showed rather large color changes after aging. The results of that study indicated that pigments should be chosen carefully if color stability is to be achieved.

Received for publication June 19, 1978 .

Accepted for publication August 22, 1978.

This research was supported in whole by USPHS Research Grant DE-04136 from National Institute of Dental Research, National Institutes of Health, Bethesda, MD 20014.
Another factor involved in color stability is the stain resistance of the base elastomers, since these appliances are frequently exposed to stains in a service environment. In fact, patients frequently will try to improve the esthetics of their appliances by the application of cosmetics.

The purpose of this study was to evaluate the staining characteristics of several maxillofacial materials by measuring the color of those materials with a reflectance spectrophotometer before and after staining. This method is similar to one described by Hill and Leonard ${ }^{3}$ in 1958 and applied to the evaluation of maxillofacial materials by Goldberg ${ }^{4}$ in 1977.

\section{Methods and materials.}

Three categories of maxillofacial materials were evaluated as described in Table 1. The samples $(3.5 \mathrm{~mm} \times 4 \mathrm{~cm} \times 6 \mathrm{~cm})$ were prepared according to the manufacturers' instructions in aluminum molds.

Three stains were chosen to evaluate the stain resistance of the elastomers: tea, lipstick, and disclosing solution. The tea stain was prepared by dissolving $3.5 \mathrm{gm}$ of tea* in $750 \mathrm{ml}$ of distilled boiling water. The solution was cooled to room temperature before immersion of the samples. The samples were suspended in the tea solution, and the solution was stirred constantly during the staining sequence. With the tea stain, all materials were evaluated at of , 1, 3, and 24 hours. The samples were washed and dried after they were removed from the tea stain and before color measurements were made.

The lipstick stain was a deep red shade. $\ddagger$ The stain was applied to the samples by hand by alternating horizontal and vertical

*Lipton Instant $100 \%$ tea, Lot. No. 7C9M, Thomas J. Lipton, Inc., Englewood Cliffs, NJ.

Zero hours refers to samples before staining.

$\$$ Big Apple, $¥ 03301$, Cover Girl Moisturized Shiny Lipsticks, Noxell Corp., Baltimore, MD. 
applications until a uniform covering was obtained. The samples were stored at room temperature during the time the stain remained on the samples. With the lipstick stain the color of the samples was measured at $0,1,3$, and 24 hours. The samples were wiped with a clean, dry cloth to remove the lipstick from the surface of the samples. The surfaces then were cleansed by hand with skin cream $\S$ until no more stain was visible on the cloth which was used to remove the cleansing agent. The samples were then washed and dried before color analysis.

The disclosing solution was prepared from 45 grams Bismark Brown stain, 1800 cc glycerine, $15 \mathrm{cc}$ of $95 \%$ ethyl alcohol, and $1 \mathrm{cc}$ of oil of anise flavoring. This was further diluted by three parts distilled water to one part disclosing solution. The solution was kept at room temperature during the test sequence and stirred constantly while the samples were suspended in the solution. The disclosing solution was a very effective stain, and it was determined that $0,1 / 2,1$, and 3 hour intervals would be adequate exposure to this stain. The samples were removed at those times and washed and dried before measuring the color of the specimens.

At the indicated time intervals, reflectance curves were obtained for the samples in a double-beam, ultraviolet-visible spectrophotometer* with a reflectance spheret in the combined specular and diffuse reflectance

§ Noxema Greaseless Skin Cream, Lot No. 0127 , Noxell Corp., Baltimore, MD.

*ACTA C III, Beckman Instruments, Inc., Irvine, CA.

†ASPH-U Integrating Sphere, Beckman Instruments, Inc., Irvine, CA. mode. The amount of light reflected at each wavelength in the visible spectrum (405 to $700 \mathrm{~nm}$ ) was measured and recorded.

The spectral response of each sample was used to calculate luminous reflectance, dominant wavelength, and excitation purity by use of a computer program $\$$ based on the C.I.E. Chromaticity Diagram 1931 and Source $A^{5}$.

Barium sulfate plates ${ }^{\infty}$ were used to calibrate the instrument, to back up the specimens when they were placed in position on the reflectance sphere, and to serve as a standard in the reference port of the sphere. Three samples of each material were used for each stain at each time interval, for a total of 36 samples for each material. Mean values and standard deviations were obtained for each condition for each material. Means were compared by analysis of variance ${ }^{6}$ and Tukey's multiple comparison test ${ }^{7}$ at a $95 \%$ level of confidence.

\section{Results.}

The results for luminous reflectance for the tea stain are shown in Table 2. The Tukey interval among times and materials was 0.45 . All materials were significantly different in luminous reflectance after 24 hours. The silicones $A$ and $C$ had very small changes of 0.6 and 1.2 , respectively, while the polyvinyl chloride $\mathrm{D}$ and the silicone $\mathrm{B}$ had slightly larger changes of 2.8 and 4.1 . Three of the materials, B, C, and D, were

the computer program is available from the author upon request.

International Commission on Illumination.

${ }^{\infty}$ Part No. 104384, Beckman Instruments, Inc., Irvine, CA.

TABLE 1

CODES, BATCH NUMBERS AND MANUFACTURERS OF PRODUCTS TESTED

\begin{tabular}{clll}
\hline Code & Product & Batch Number & Manufacturer \\
\hline $\begin{array}{c}\text { RTV Silicones: } \\
\text { A }\end{array}$ & Silastic 44210 & Base - 44CO74 & Dow Corning Corp. \\
& Silastic 382 & Catalyst-HHP094 & Midland, MI \\
B & & Base - HHN262 & Dow Corning Corp.
\end{tabular}

Heat Vulcanized Silicone:

C

Polyvinyl Chloride:
Silastic 44515

Prototype III
HHB 148

Dow Corning Corp.
184-21
Sartomer Industries

Essington, PA 
TABLE 2

SPECTROPHOTOMETRIC PARAMETERS OF FOUR MAXILLOFACIAL MATERIALS AS A FUNCTION OF TIME FOR TEA STAIN*

\begin{tabular}{|c|c|c|c|c|}
\hline \multirow[b]{2}{*}{ Code } & \multicolumn{4}{|c|}{ LUMINOUS REFLECTANCE } \\
\hline & $0 \mathrm{HR}$ & $1 \mathrm{HR}$ & $3 \mathrm{HR}$ & $24 \mathrm{HR}$ \\
\hline A & $84.6(0.3)$ & $86.0(0.1)$ & $85.7(0.4)$ & $85.2(0.4)$ \\
\hline B & $81.3(0.2)$ & $80.6(0.3)$ & $79.5(0.3)$ & $77.2(0.6)$ \\
\hline $\mathrm{C}$ & $71.6(0.3)$ & $71.6(1.3)$ & $71.9(1.5)$ & $70.4(1.0)$ \\
\hline \multirow[t]{2}{*}{ D } & $76.4(1.0)$ & $76.0(0.9)$ & $76.2(0.7)$ & $73.6(0.6)$ \\
\hline & \multicolumn{4}{|c|}{ DOMINANT WAVELENGTH in $\mathrm{nm}$} \\
\hline Code & $0 \mathrm{HR}$ & $1 \mathrm{HR}$ & $3 \mathrm{HR}$ & $24 \mathrm{HR}$ \\
\hline A & $582.8(0.2)$ & $583.6(0.2)$ & $583.4(0.2)$ & $583.6(0.1)$ \\
\hline B & $583.8(0.0)$ & $583.6(0.0)$ & $583.6(0.1)$ & $582.2(0.2)$ \\
\hline $\mathrm{C}$ & $585.0(0.5)$ & $585.6(0.2)$ & $585.4(0.2)$ & $585.1(0.1)$ \\
\hline \multirow[t]{2}{*}{$\mathrm{D}$} & $583.7(2.0)$ & $583.1(0.2)$ & $582.9(0.1)$ & $581.1(0.1)$ \\
\hline & \multicolumn{4}{|c|}{ EXCITATION PURITY } \\
\hline Code & $0 \mathrm{HR}$ & $1 \mathrm{HR}$ & $3 \mathrm{HR}$ & $24 \mathrm{HR}$ \\
\hline A & $0.042(0.004)$ & $0.049(0.002)$ & $0.048(0.000)$ & $0.049(0.001)$ \\
\hline B & $0.124(0.001)$ & $0.134(0.003)$ & $0.136(0.002)$ & $0.151(0.004)$ \\
\hline $\mathrm{C}$ & $0.140(0.013)$ & $0.120(0.007)$ & $0.134(0.020)$ & $0.166(0.007)$ \\
\hline $\mathrm{D}$ & $0.096(0.009)$ & $0.105(0.006)$ & $0.114(0.006)$ & $0.136(0.006)$ \\
\hline
\end{tabular}

*Mean of three replications with standard deviations in parentheses. Tukey's intervals at the $95 \%$ level of confidence for comparisons of means among times and among materials were 0.45 for luminous reflectance, $1.5 \mathrm{~nm}$ for dominant wavelength, and 0.008 for excitation purity.

darker after staining, while A was slightly lighter.

Only two materials changed in dominant wavelength with the tea stain, and these changes were small (see Table 2 ). Product B changed from 583.8 to $582.2 \mathrm{~nm}$ after 24 hours of exposure to the tea stain, and D changed from 583.7 to $581.1 \mathrm{~nm}$. The Tukey interval for time was $1.5 \mathrm{~nm}$.

The effect of the tea stain on the excitation purity of the materials is seen in Table 2. The Tukey interval among times and materials was 0.008 . Product A did not change in excitation purity when exposed to the tea stain. Product $\mathrm{C}$ showed an initial decrease from 0.140 at 0 hours to 0.120 at 1 hour and then increased to 0.166 after 24 hours. The silicones B and $C$ had similar changes in excitation purity of 0.027 and 0.026 , respectively. The polyvinyl chloride $D$ had the largest change in excitation purity after 24 hours at 0.040 .

The results for luminous reflectance for the lipstick stain on the materials studied are shown in Table 3. The luminous reflectance of all materials changed significantly after 24 hours of exposure to the lipstick stain. Product D had the smallest change at 5.5 after 24 hours, and B had the largest change at 7.6. These changes were larger than those seen with the tea stain, which ranged from 0.6 to 4.0 .

The values of dominant wavelength for the lipstick stain are listed in Table 3. The changes in dominant wavelength were large after only 1 hour of exposure to the stain ranging from 3.5 to $17.3 \mathrm{~nm}$. The smallest change in dominant wavelength after 24 hours was seen with $D$ at $18.9 \mathrm{~nm}$. The largest change was observed with $A$ which changed from $583.2 \mathrm{~nm}$ at 0 hours to a complementary wavelength of $509.7 \mathrm{~nm}$ after 24 hours of exposure to the lipstick. As expected, the dominant wavelengths moved toward the red region of the visible spectrum for all materials evaluated.

The results for excitation purity for the lipstick stain are shown in Table 3. Products $A$ and $D$ demonstrated no change in excitation purity during the 24 hours of exposure to the lipstick stain. The excitation purity decreased during the test sequence for $B$ and $C$. For all materials, the changes in excitation purity after 24 hours were small and ranged from 0.003 to 0.042 .

The effect of disclosing solution on the 
TABLE 3

SPECTROPHOTOMETRIC PARAMETERS OF FOUR MAXILLOFACIAL MATERIALS AS A FUNCTION OF TIME FOR LIPSTICK STAIN*

\begin{tabular}{|c|c|c|c|c|}
\hline \multirow[b]{2}{*}{ Code } & \multicolumn{4}{|c|}{ LUMINOUS REFLECTANCE } \\
\hline & $0 \mathrm{HR}$ & $1 \mathrm{HR}$ & $3 \mathrm{HR}$ & $24 \mathrm{HR}$ \\
\hline A & $84.9(0.2)$ & $83.3(0.7)$ & $82.9(0.5)$ & $79.0(0.5)$ \\
\hline B & $81.2(0.4)$ & $80.4(0.2)$ & $79.4(0.9)$ & $73.6(0.5)$ \\
\hline C & $72.3(0.3)$ & $71.9(0.7)$ & $68.8(0.4)$ & $65.4(0.4)$ \\
\hline \multirow[t]{2}{*}{ D } & $77.3(0.2)$ & $76.9(0.4)$ & $75.4(1.1)$ & $71.8(0.5)$ \\
\hline & \multicolumn{4}{|c|}{ DOMINANT WAVELENGTH in $\mathrm{nm}$} \\
\hline Code & $0 \mathrm{HR}$ & $1 \mathrm{HR}$ & $3 \mathrm{HR}$ & $24 \mathrm{HR}$ \\
\hline A & $583.2(0.1)$ & $600.5(0.6)$ & $623.4(11)$ & $-509.7(0.6)$ \\
\hline B & $582.8(0.6)$ & $586.3(0.2)$ & $588.8(2.6)$ & $614.0(3.2)$ \\
\hline $\mathrm{C}$ & $585.4(0.3)$ & $589.7(0.4)$ & $592.7(0.7)$ & $608.1(1.2)$ \\
\hline \multirow[t]{2}{*}{$\mathrm{D}$} & $584.0(1.2)$ & $588.0(0.4)$ & $590.1(0.1)$ & $602.9(0.1)$ \\
\hline & \multicolumn{4}{|c|}{ EXCITATION PURITY } \\
\hline Code & $0 \mathrm{HR}$ & $1 \mathrm{HR}$ & $3 \mathrm{HR}$ & $24 \mathrm{HR}$ \\
\hline A & $0.042(0.001)$ & $0.03690 .001)$ & $0.033(0.003)$ & $0.039(0.001)$ \\
\hline B & $0.124(0.003)$ & $0.120(0.001)$ & $0.118(0.013)$ & $0.091(0.002)$ \\
\hline $\mathrm{C}$ & $0.136(0.014)$ & $0.128(0.004)$ & $0.120(0.016)$ & $0.094(0.002)$ \\
\hline D & $0.093(0.005)$ & $0.085(0.001)$ & $0.092(0.003)$ & $0.091(0.004)$ \\
\hline
\end{tabular}

* Mean of three replications with standard deviations in parentheses. Tukey's intervals at the $95 \%$ level of confidence for comparisons of means among times and among materials were 0.45 for luminous reflectance, $1.5 \mathrm{~nm}$ for dominant wavelength, and 0.008 for excitation purity.

materials is shown in Table 4 . The time intervals of $1 / 2,1$, and 3 hours were chosen for this stain because it was particularly effective and it was felt that longer exposure was not necessary. All of the materials had a luminous reflectance which was significantly lower after three hours of exposure to this stain. In fact, three of the materials had significant changes in luminous reflectance after $1 / 2$ hour of exposure ranging from 1.7 to 8.3 . Only A showed no change after $1 / 2$ hour. As a group, the silicones had small changes after 3 hours ranging from 2.0 for $A$ to 3.9 for $\mathrm{C}$. The polyvinyl chloride $D$ demonstrated dramatic changes in luminous reflectance with a change of 8.3 after $1 / 2$ hour and 36.2 after 3 hours' exposure to the stain.

For the disclosing solution, changes in dominant wavelength were small as seen in Table 4. Only D changed significantly after 3 hours of exposure to the stain from 584.0 to $592.3 \mathrm{~nm}$.

The results for excitation purity for the disclosing solution are seen in Table 4. All materials demonstrated significant changes after $1 / 2$ hour of exposure to the stain, ranging from 0.083 for $\mathrm{B}$ to 0.675 for $\mathrm{D}$. Product B changed 0.115 after 3 hours, while $C$ changed by 0.377 . Product D demonstrated a very large change in excitation purity after three hours of 0.777 .

\section{Discussion.}

For this study the spectrophotometer was well suited for measuring the color changes of the elastomers caused by the stains. Very small changes in color could be detected by this instrumentation.

The tea, lipstick, and disclosing solution were chosen for this study because of their diverse chemistry and proven staining characteristics. Many other stains are available, and in future studies they will be included when feasible.

The changes in luminous reflectance for the materials and stains studied were varied. Tea produced subtle but significant changes in luminous reflectance, while lipstick and disclosing solution produced much larger changes. Overall A had the smallest changes in luminous reflectance with all stains. Products B, C, and D demonstrated changes 
TABLE 4

SPECTROPHOTOMETRIC PARAMETERS OF FOUR MAXILLOFACIAL MATERIALS AS A FUNCTION OF TIME FOR DISCLOSING SOLUTION*

\begin{tabular}{lcccc}
\hline & & & \multicolumn{2}{c}{ LUMINOUS REFLECTANCE } \\
Code & $0 \mathrm{HR}$ & $0.5 \mathrm{HR}$ & $1 \mathrm{HR}$ & $3 \mathrm{HR}$ \\
\cline { 2 - 5 } $\mathrm{A}$ & $84.4(0.7)$ & $84.8(0.3)$ & $84.0(0.3)$ & $82.4(0.2)$ \\
$\mathrm{B}$ & $81.1(0.4)$ & $79.4(0.2)$ & $80.2(0.1)$ & $78.1(0.2)$ \\
$\mathrm{C}$ & $71.4(0.7)$ & $69.4(1.7)$ & $69.5(1.1)$ & $67.5(0.8)$ \\
$\mathrm{D}$ & $76.6(0.1)$ & $68.3(0.8)$ & $64.9(0.8)$ & $40.4(1.1)$
\end{tabular}

\begin{tabular}{|c|c|c|c|c|}
\hline \multirow[b]{2}{*}{ Code } & \multicolumn{4}{|c|}{ DOMINANT WAVELENGTH in $\mathrm{nm}$} \\
\hline & $0 \mathrm{HR}$ & $0.5 \mathrm{HR}$ & $1 \mathrm{HR}$ & $3 \mathrm{HR}$ \\
\hline A & $583.2(0.0)$ & $583.7(0.1)$ & $583.8(0.1)$ & $583.0(0.3)$ \\
\hline B & $583.4(0.1)$ & $584.0(0.1)$ & $584.1(0.1)$ & $584.6(0.2)$ \\
\hline $\mathrm{C}$ & $585.3(0.1)$ & $585.4(0.2)$ & $585.5(0.1)$ & $585.3(0.1)$ \\
\hline D & $584.0(1.4)$ & $584.1(0.2)$ & $584.8(0.2)$ & $592.3(2.1)$ \\
\hline
\end{tabular}

\begin{tabular}{lcccc} 
& \multicolumn{4}{c}{ EXCITATION PURITY } \\
Code & $0 \mathrm{HR}$ & $0.5 \mathrm{HR}$ & $1 \mathrm{HR}$ & $3 \mathrm{HR}$ \\
\cline { 2 - 5 } A & $0.042(0.001)$ & $0.160(0.002)$ & $0.191(0.019)$ & $0.351(0.073)$ \\
B & $0.125(0.003)$ & $0.208(0.004)$ & $0.213(0.001)$ & $0.240(0.009)$ \\
C & $0.114(0.008)$ & $0.270(0.006)$ & $0.296(0.023)$ & $0.491(0.008)$ \\
D & $0.098(0.008)$ & $0.773(0.018)$ & $0.807(0.007)$ & $0.875(0.008)$ \\
\hline
\end{tabular}

*Mean of three replications with standard deviations in parentheses. Tukey's intervals at the $95 \%$ level of confidence for comparisons of means among times and among materials were 0.45 for luminous reflectance, $1.5 \mathrm{~nm}$ for dominant wavelength, and 0.008 for excitation purity.

of similar magnitude with the tea and lipstick stains; however, when disclosing solution was used, D had a very large change in luminous reflectance compared to all other materials.

The changes in excitation purity caused by tea and lipstick were of a similar magnitude for all materials, and they were low ranging from 0.007 to 0.040 for tea and from 0.002 to 0.042 for lipstick. Disclosing solution caused large changes in excitation purity, ranging from 0.115 to 0.777 .

Only lipstick was consistently effective in changing the dominant wavelength of the materials used in this study. It was interesting that $\mathbf{A}$ had a very large change in dominant wavelength with the lipstick stain, when it had good to excellent stain resistance with tea and disclosing solution. However, it must be pointed out that although the change in dominant wavelength was large for A, the excitation purity was very low. At a low excitation purity, large changes in dominant wavelength are not easily perceptible. Product D had the smallest change in dominant wavelength with the lipstick, but demonstrated large changes in all cate- gories with the disclosing solution.

Interpreting the results of stain resistance of maxillofacial materials is complex and difficult. Many factors may be responsible for the staining characteristics demonstrated in this study, such as the type and percentage of fillers, the presence of plasticizers, the wettability of the material by the stain, and the chemistry of the elastomers and stains. Further research needs to be done on the mechanisms of staining, if the stain resistance of the elastomers is to be improved.

\section{Conclusions.}

Tea, lipstick, and disclosing solution were effective in testing the stain resistance of the elastomers. All of the maxillofacial materials studied had individual staining characteristics. For example, while a silicone (A) had the best stain resistance with tea and good stain resistance with disclosing solution, it demonstrated the largest change in dominant wavelength with the lipstick stain.

The changes in luminous reflectance, dominant wavelength, and excitation purity 
for tea, lipstick, and disclosing solution were much larger than those seen in previous studies, which evaluated the color stability of the base elastomers and maxillofacial pigments under conditions of accelerated aging. These results indicate that staining of maxillofacial materials in a service environment may be largely responsible for the color changes which necessitate replacement of the appliances.

\section{REFERENCES}

1. CRAIG, R. G.; KORAN, A.; and YU, R.: Color stability of elastomers for maxillofacial appliances. Prog and Abstracts of Papers, $J$ Dent Res Spec. Iss. A:A173, 1977.

2. KORAN, A.; YU, R.; POWERS, J. M.; and
CRAIG, R. G.: Color stability of a pigmented elastomer for maxillofacial appliances. Prog and Abstracts of Papers, $J$ Dent Res Spec. Iss. B:B150, 1977.

3. HILL, J. T.; and LEONARD, F.: Determining discoloration of rubberlike films by reflectance spectrophotometry. Rubber Age, 84:268-74, 1958.

4. GOLDBERG, A. JON: Polyurethane elastomers as maxillofacial prosthetic materials. Ph.D. Dissertation, Ann Arbor, University of Michigan, 1977.

5. WYSZECKI, G.; and STILES, W. S.: Color Science. New York, Wiley and Sons, Inc., 1967. $628 \mathrm{pp}$.

6. DALBY, JOHN, programmer: BMD8V-Analysis of variance. Ann Arbor, Statistical Research Laboratory, 1968, $4 \mathrm{pp}$.

7. GUENTHER, W.C.: Analysis of variance. Englewood Cliffs, NJ, Prentice-Hall, Inc., 1964. $141 \mathrm{pp}$.

\section{ERRATUM}

Following is a corrected table provided by Dennison and Powers for their research annotation, "Physical Properties of Pit and Fissure Sealants" ( $J$ Dent Res 58(4):1430, 1979):

TABLE 2

WATER SORPTION OF PIT AND FISSURE SEALANTS*

\begin{tabular}{|c|c|c|}
\hline \multirow[b]{2}{*}{ Material } & \multicolumn{2}{|c|}{ Water Sorption $\left(\mathrm{mg} / \mathrm{cm}^{2}\right)$} \\
\hline & 24 Hrs. & $1 \mathrm{Wk}$. \\
\hline $\mathrm{K}$ & $0.73(0.06)$ & $1.34(0.02)$ \\
\hline NS & $0.98(0.01)$ & $1.57(0.10)$ \\
\hline D & $1.29(0.10)$ & $2.04(0.22)$ \\
\hline W & $1.21(0.12)$ & $1.92(0.23)$ \\
\hline V & $0.42(0.18)$ & $0.79(0.10)$ \\
\hline$S$ & $1.58(0.27)$ & $2.03(0.30)$ \\
\hline
\end{tabular}

* Means with standard deviations in parentheses. Tukey intervals $(\alpha=0.05)$ for comparisons among products and between times were 0.22 and 0.15 $\mathrm{mg} / \mathrm{cm}^{2}$, respectively. 